Proc. Indian Acad. Sci. (Earth Planet. Sci.). Vol. 92. Number 1, March 1983, pp. 5-13.

(C) Printed in India.

\title{
Worldwide features of the strength of recurrent geomagnetic activity
}

\author{
G K RANGARAJAN and A BHATTACHARYYA \\ Indian Institute of Geomagnetism, Colaba, Bombay 400005 , India.
}

MS received 4 August 1982

\begin{abstract}
Variation of the strength of recurrent geomagnetic activity, which occurs just before a sunspot minimum, with local time is studied for a network of observatories covering different latitude and longitude zones. For this purpose, hourly averages of horizontal inten$\operatorname{sity}(H)$ for each UT hour for 173 days. which are totally free of disturbances due to solar transients, have been subjected to spectral analysis. Well-defined spectral peaks associated with periodicities of 28,14 and 9 days were present in almost all the spectra. The pattern of daily variation of the strength of the 27-day signal changes from a diurnal one at low latitudes to a semi-diurnal one near the $\mathrm{Sq}$ focus and in this region, the 14-day signal appears to have an independent origin irrespective of the longitude 7one. A study of 27-day oscillation in mean daily $H$ field also indicates that apart from ring current modulation, both $\mathrm{Sq}$ and electrojet fields also undergo 27-day oscillations during the declining phase of a solar cycle possibly through the ionospheric wind system.
\end{abstract}

Keywords. Worldwide features; geomagnetic activity: sunspot minimum: ring current; tidal winds.

\section{Introduction}

The strength of recurrent geomagnetic activity, as measured by the amplitude of 27-day oscillation in the mean daily values of horizontal magnetic field has been studied in the equatorial region for different phases of solar activity (Bhargava and Rao 1970). Recurrent activity before sunspot minimum is now known to have features quite distinct from activity during other phases of the solar cycle (Legrand and Simon 1981). Bhargava (1973) and Bhargava and Rangarajan (1975) have studied the evening forenoon asymmetry in the amplitude of the 27-day oscillations of horizontal magnetic field at Alibag (dipole lat. $9.5 \mathrm{~N}$ ) both during the declining phase of solar cycle just before minimum and during high solar activity. The asymmetry in signal strength was attributed to the corresponding diurnal asymmetry in the equatorial ring current intensity.

In order to study noise-free 27-day signal of recurrent activity it is essential to pick an interval free of disturbances from other solar transients. One such interval has been identified by Hansen et al (1976), who found that the period extending from midDecember 1973 to mid-June 1974 shows a highly persistent pattern of geomagnetic activity without any SSCs: flares and other transient activities were totally absent. Van Hollebeke et al (1981) recently studied in detail the relationship between energetic particle events and high speed solar wind for the period November 1973 to August 1974, during which two well-defined recurring high speed streams were seen to persist for nearly 10 solar rotations. 
Studies on the low latitude field signals of the 27-day oscillation referred to earlier utilised data over longer time spans of 2-3 years during which period solar transients could also have contributed to geomagnetic activity. As pointed out by Hansen et al (1976) such geomagnetic activity would be positively correlated with solar features which tend to reverse or destroy the signal of recurrent activity as this type of activity is found to be inversely related to the intensity of coronal structures.

In this paper we carry out a systematic search for the local-time and latitude dependance of the 27-day geomagnetic signal due mainly to recurrent solar features using horizontal intensity observations for the period 20 December 1973 to 10 June 1974 (Bartels rotation No. 1920 to 1926) of a carefully selected network of observatories. The coordinates of the stations chosen are given in table 1 . In the Indian zone, the stations cover the region between the equatorial electrojet belt to just above the northern $\mathrm{Sq}$ focus. Inclusion of Nurmijarvi-dipole conjugate of Kerguelen-in the analysis was necessitated to establish the anomalous nature of the 27-day oscillation at Kerguelen, an island in the southern hemisphere.

\section{Data analysis}

Hourly averages of horizontal intensity $(H)$ for each UT hour for the period 20 December 1973 to 10 June 1974 (173 days) were used in spectral analysis using a version of FFT described in detail in Rangarajan and Bhargava (1974), adopting 0.002 as bandwidth for each spectral estimate. Some sample power spectra at two stationsTrivandrum and Alibag-are shown in figure 1. For each station, two spectra are depicted, one for that particular hour when the strength of the 27-day signal is close to a minimum and another for the hour when the power spectral density associated with the 27-day signal is maximum. In almost all the spectra there were well-defined spectral peaks, above the continuum, corresponding to the periodicities of 28,14 and 9 days. Power densities associated with these periodicities, representing the solar synodic rotation periodicity and its first harmonic, for each hour are noted. These are depicted in figures 2 to 6.

Table 1. Geographic and dipole coordinates of observatories used in the analysis.

\begin{tabular}{|c|c|c|c|c|c|}
\hline \multirow[b]{2}{*}{ Station Name } & \multirow[b]{2}{*}{ Code } & \multicolumn{2}{|c|}{ Geographic } & \multicolumn{2}{|c|}{ Dipole } \\
\hline & & Latitude & Longitude & Latitude & Longitude \\
\hline Trivandrum & TRD & $8^{\circ} 29^{\prime} \mathrm{N}$ & $76^{\circ} 57^{\prime} \mathrm{E}$ & $1.1^{\circ} \mathrm{S}$ & $146.4^{\circ}$ \\
\hline Alibag & ABG & $18^{\circ} 38^{\prime} \mathrm{N}$ & $72^{\circ} 52^{\prime} \mathrm{E}$ & $9.5^{\circ} \mathrm{N}$ & $143.6^{\circ}$ \\
\hline Sabhawala & SAB & $30^{\circ} 20^{\prime} \mathrm{N}$ & $77^{\circ} 48^{\prime} \mathrm{E}$ & $20.5^{\circ} \mathrm{N}$ & $149.7^{\circ}$ \\
\hline Tashkent & TKT & $41^{\circ} 20^{\prime} \mathrm{N}$ & $69^{\circ} 37^{\prime} \mathrm{E}$ & $32.3^{\circ} \mathrm{N}$ & $144.0^{\circ}$ \\
\hline Lunping & LNP & $25^{\circ} 00^{\prime} \mathrm{N}$ & $121^{\circ} 10^{\prime} \mathrm{E}$ & $13.8^{\circ} \mathrm{N}$ & $189.5^{\circ}$ \\
\hline Simosato & sso & $33^{\circ} 34^{\prime} \mathrm{N}$ & $135^{\circ} 56^{\prime} \mathrm{E}$ & $23.0^{\circ} \mathrm{N}$ & $202.4^{\circ}$ \\
\hline Memambetsu & MMB & $43^{\circ} 55^{\prime} \mathrm{N}$ & $144^{\circ} 12^{\prime} \mathrm{E}$ & $34.0^{\circ} \mathrm{N}$ & $208.4^{\circ}$ \\
\hline Teoloyucan & TEO & $19^{\circ} 45^{\prime} \mathrm{N}$ & $99^{\circ} 11^{\prime} \mathrm{W}$ & $29.6^{\circ} \mathrm{N}$ & $327.0^{\circ}$ \\
\hline Hartebeesthoek & HBT & $25^{\circ} 53^{\prime} \mathrm{S}$ & $27^{\circ} 42^{\prime} \mathrm{E}$ & $26.9^{\circ} \mathrm{S}$ & $87.8^{\circ}$ \\
\hline Hermanus & HER & $34^{\circ} 25^{\prime} \mathrm{S}$ & $19^{\circ} 14^{\prime} \mathrm{E}$ & $33.7^{\circ} \mathrm{S}$ & $81.7^{\circ}$ \\
\hline Kerguelen & KGL & $49^{\circ} 21^{\prime} \mathrm{S}$ & $70^{\circ} 12^{\prime} \mathrm{E}$ & $56.5^{\circ} \mathrm{S}$ & $127.8^{\circ}$ \\
\hline Nurmijarvi & NUR & $60^{\circ} 30^{\prime} \mathrm{N}$ & $24^{\circ} 39^{\prime} \mathrm{E}$ & $57.8^{\circ} \mathrm{N}$ & $112.6^{\circ}$ \\
\hline
\end{tabular}




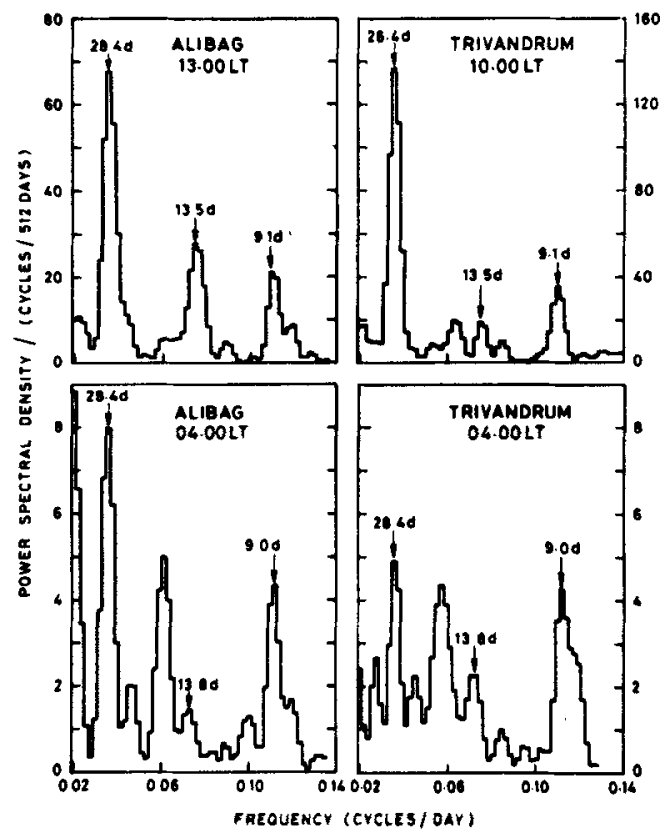

Figure 1. Power spectra of series of hourly averages for two particular hours at Trivandrum and Alibag.

\section{Results and discussion}

\subsection{7-day and 14-day signal in Indian zone}

All the stations in the Indian zone are within $6^{\circ}$ of $75^{\circ} \mathrm{E}$ longitude so that the local time may be taken to be 5 hours ahead of UT. Power densities at the two frequencies as a function of local time for four stations are shown in figure 2. The graphs at once suggest a strong dependance of the solar rotation signal on time of day with peak magnitude being a function of latitude. Close to the dip equator the power density varies from about $10 \mathrm{nT}^{2}$ (unit bandwith) at predawn hour to a peak value of about $135 \mathrm{nT}^{2}$ before local noon. At low latitude (Alibag) the power density varies between about 5 and $70 \mathrm{nT}^{2}$ and the time of peak amplitude shifts to post-noon hours, similar to the earlier results of Bhargava (1973). At both Trivandrum and Alibag the local time change is dominantly diurnal in contrast to the stations close to and on either side of the Sq focus. At Sabhawala and Tashkent, in addition to the early afternoon peaks (similar to Alibag) a forenoon secondary maximum becomes apparent. This semidiurnal pattern in strength of the 27-day signal is similar to the $\mathrm{Sq}(H)$ variation at Sabhawala having a 12 -hr periodicity comparable in amplitude to the diurnal component (Srivastava and Prasad 1979; Rangarajan and Ahmed 1981). The reduction in peak power-density as a function of latitude $(\theta)$ is not matched by the $\cos ^{2} \theta$ dependance of ring current effect indicating that the 27-day oscillation and its equatorial enhancement cannot be fully explained by the ring current intensity modulation alone. Bhargava and Rao (1970) found that during the declining phase (1961-63) of solar cycle 19, the power density of the solar rotation signal was comparable at Alibag 


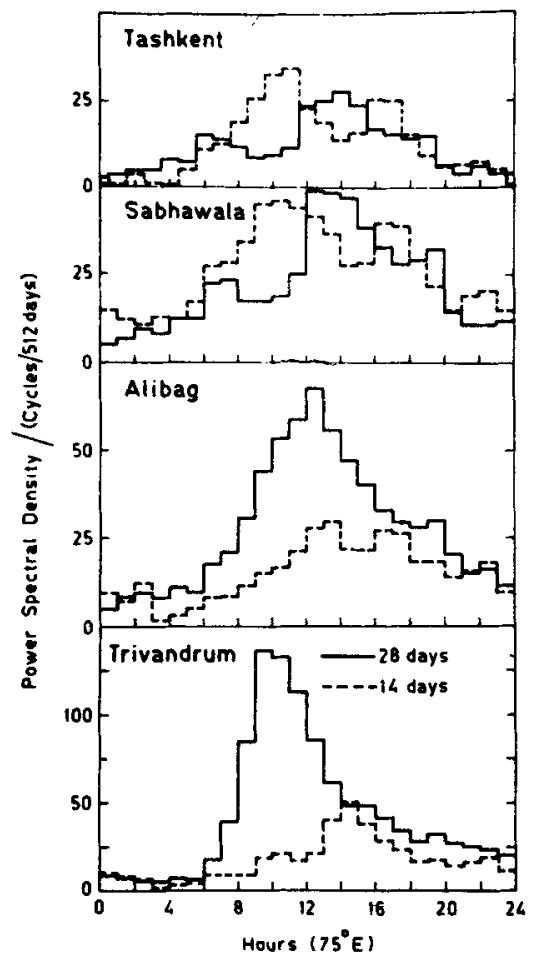

Figure 2. Power spectral densities for 28-day and 14-day signals as functions of $75^{\circ} \mathrm{E}$ time for stations in the Indian zone.

and Trivandrum. The present results, on the other hand, clearly show an enhancement by a factor of 2 in the peak power close to noon time. These differences can be attributed to the fact that when the data covering a large time-span and mean daily values are utilized, the significant features and fine structure could be obscured due to the opposite relationship of solar transients and stable coronal activity as indicated by Hansen et al (1976). The difference in time of peak power between electrojet and low latitude station outside the belt is consistent with the suggestion of Onwumechilli (1967) that the electrojet field leads the Sq field by more than an hour. It is known that harmonics of fundamental periodicities appear in the spectrum because of nonsinusoidal nature of the variations. If the 14-day spectral line were only a harmonic of the basic 28-day periodicity the local time behaviour of the amplitude at this frequency will be expected to be similar with reduced magnitude at all hours. Examination of the LT pattern for the 14-day line clearly indicates that while this expectation is largely fulfilled at Alibag, close to the Sq focus (and on either side of it) there is clear evidence that the significant oscillation of the $H$ field has a basic periodicity of 14 days.

Recently Briggs (1979) showed that a 27 -day oscillation could be noticed in the mid-latitude solar daily variation field $\left(S_{R}\right)$, markedly so during the declining phase of the solar cycle. To eliminate magnetospheric part he took the difference of the $H$ field at two nearby stations. He suggested that the effect may be mainly due to a 27-day recurrence tendency in the amplitude of the tidal winds in the dynamo region. As the power densities and the local time variations obtained in our analysis are suggestive of significant contribution from the Sq field, we have computed the power spectra for the 
differences (TRD-ABG) and (ABG-SBH) (see table 1 for station codes) for the same period. The corresponding variations are depicted in figure 3 . Rush and Richmond (1973) and Kane (1978) have shown that such differencing procedure for stations in the same longitude zone but separated in latitude give the time variations of only the ionospheric (electrojet or $\mathrm{Sq}$ ) part of the field as the magnetospheric contribution is largely removed.

Significant power at the solar rotation frequency confined to just a few hours before local noon for the (TRD-ABG) data clearly indicates a 27-day oscillation of the electrojet strength. The signal derived from (ABG-SAB) difference, indicative of $\mathrm{Sq}$ field of ionospheric origin, has nearly the same magnitude for peak power. It may, therefore, be inferred that apart from ring current modulation, both Sq and electrojet field also undergo 27-day oscillations during the declining phase. As the magnitudes of the two are comparable, it is quite likely that the ionospheric wind system rather than the electrical conductivity shows similar oscillations as inferred by Briggs (1979). Electrical conductivity is more likely to be affected during periods of high solar activity.

\subsection{Comparison of 27-day signal at a pair of stations in day and night hemispheres}

The two magnetic stations, Alibag and Teoloyucan, are located nearly in the same geographic latitude and differ by nearly $180^{\circ}$ in longitude. The pair is thus suitable to establish clearly whether the strength of the signal depends on universal (UT) or local time (LT). Power density change of the 27-day signal as a function of local time for these two stations are shown in figure 4. It is immediately seen that at low latitudes the variation is governed by local time (LT) with peak power close to local noon. There is a noticeable difference in the power between the two stations during the afternoon hours. This may be because of the difference in their dipole latitudes, with Teoloyucan being higher by about $20^{\circ}$, leading to a reduction in the magnitude of the contribution of the asymmetric ring current envisaged as the responsible mechanism for the forenoon/ evening asymmetry at Alibag by Bhargava (1973). However a similar difference in strength of asymmetry is not reflected in the chain of Indian zone (figure 2). In fact, as has been pointed out earlier in this paper, at Sabhawala and Tashkent the daily variation pattern for the strength of the 27-day signal assumes a semi-diurnal form,

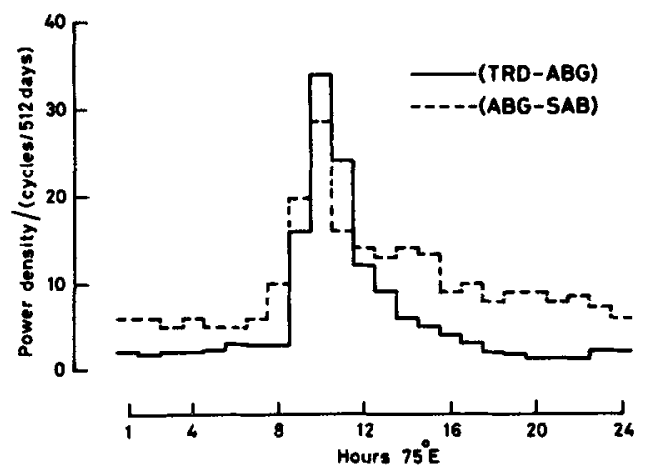

Figure 3. Power spectral density of the 28-day signal as a function of $75^{\circ} \mathrm{E}$ time for the differences (TRD-ABG) and (ABG-SAB) 


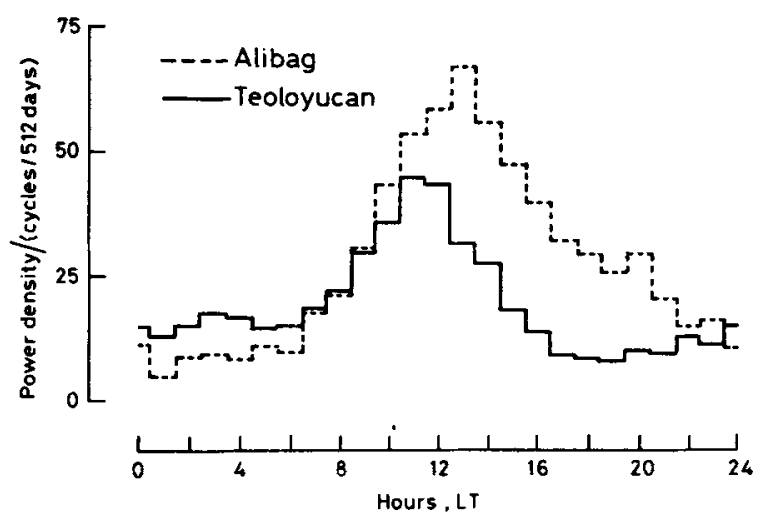

Figure 4. Power spectral density of the 28-day signal as a function of local time for the stations Alibag and Teoloyucan.

whereas at Teoloyucan it is diurnal. This goes to show that the position of Sq focus becomes important for the quite time currents which prevail during a period of low sunspot activity. Dip latitude will play a major role in disturbance fields. In the present context the effect appears to be a combination of geographic and dip latitudinal dependances.

In recent tımes it has been suggested (Crooker and Siscoe 1981) that since the dusk-centred partial ring current hypothesis for low latitude asymmetry in the disturbance field suffers from ionospheric closure and orientation problems, it should be abandoned in favour of a system of distributed Birkeland currents. Fukushima and Kamide (1973) estimated the contribution of Birkeland currents to longitudinal asymmetry at various geomagnetic latitudes from $0^{\circ}$ to $40^{\circ}$ using a partial ring current system which would consist of a west-ward flowing partial ring current in the equatorial plane, the field-aligned Birkeland current and an east-ward electrojet in the auroral zone ionosphere. They found that the contribution of Birkeland currents to the asymmetry is larger than that of the partial ring current. However, whereas the contribution of the partial ring current decreases with increasing geomagnetic latitude, that of the Birkeland currents increases with increasing geomagnetic latitude. The total asymmetry due to the whole current system (including the electrojet in the auroral zone) was found by these authors, to decrease with increasing geomagnetic latitude in their model calculation we point out that if the asymmetry is attributed to Birkeland currents alone it may be difficult to explain a decrease in the asymmetry with increasing geomagnetic latitude as we find above in the case of Alibag and Teoloyucan. A more thorough study of the asymmetry at different latitudes is required in order to arrive at a current system responsible for the low-latitude asymmetry.

\subsection{7-day oscillation in the Japanese sector}

The three stations chosen in this sector are between 8 and $9 \mathrm{hr}$, east of Greenwich and separated by about $4 \mathrm{hr}$ from the Indian zone. The power density changes with time of the day are shown in figure 5. Similar to the Indian zone, the peak power falls off systematically with increasing latitude and the local time dependance changes from a dominantly diurnal to a dominantly semidiurnal mode. The pattern of the 14-day 


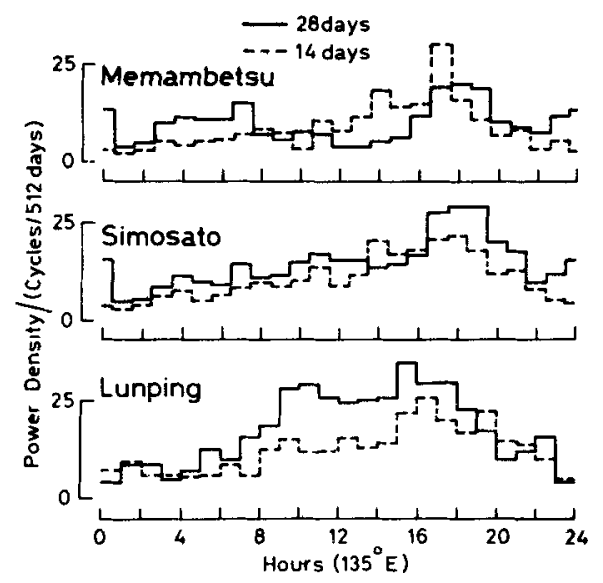

Figure 5. Power densities for 28-day and 14-day signals as functions of $135^{\circ} \mathrm{E}$ time for stations in the Japanese sector.

spectral power again indicates it to be an independent periodicity close to the $\mathrm{Sq}$ focus. Thus it may be inferred that for a fairly wide longitudinal region in northern hemisphere, the local-time and latitudinal modulation of the solar signal are similar and consistent.

\subsection{7-day oscillation of the field in southern hemisphere}

The local-time change in power densities of the 27- and 14-day spectral lines for three selected southern hemisphere stations are shown in figure 6 . The noteworthy aspect of the plot is the significant reduction in the peak power density at low latitude station, Hartebeesthoek, when compared to the stations in the Indian zone. Similar northsouth asymmetry has been shown to exist in irregular geomagnetic activity by Mayaud (1970) and Rangarajan (1979). At Hermanus, close to southern Sqfocus, the amplitude variations are again semidiurnal, while at lower latitude it is diurnal. At Kerguelen, located further south, amplitude of the solar rotation signal appears highly anomalous. The peak power of $150 \mathrm{nT}^{2}$ at dawn is comparable to the noon values in electrojet region (Trivandrum). With increasing daylight, the power density rapidly diminishes reducing almost to zero indicative of a completely different generating mechanism for the field oscillation at this location in contrast to that at other latitudes. In crder to check whether the anomalous features are observable at a geomagnetically conjugate station, the data for Nurmijarvi were also analysed. Power density variations with time for the 27-day line, also shown in figure 6, are radically different both in magnitude and diurnal pattern as compared to Kerguelen. The magnitude at Kerguelen is comparable to other locations at lower latitudes, bringing out clearly the anomalous nature of long-period oscillations at Kerguelen. The significant difference between Kerguelen and other stations utilized in the analysis, is that it is located in the middle of the Indian ocean as an isolated island. The fact that even in the mean daily values of the field the conjugate station Nurmijarvi has a significantly reduced magnitude ( $\sim 5 \mathrm{nT}^{2}$ compared to $\sim 16 n T^{2}$ at Kerguelen) suggests that the anomaly must arise from the current systems associated with island stations (Price 1969). Greater insight into this aspect can be obtained when the analysis is extended to cover 


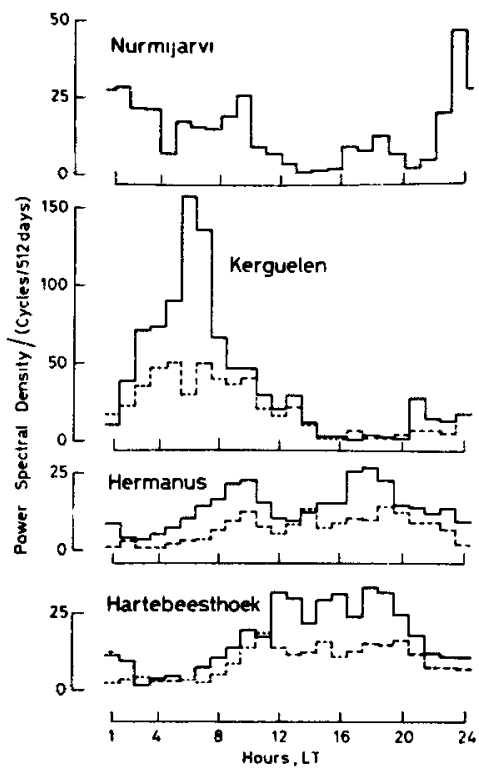

Figure 6. Power spectral densities for 28-day and 14-day signals as functions of local time for three stations in the southern hemisphere are shown in the three lower diagrams. The topmost diagram shows the power density for the 28-day signal as a function of local time for Nurmijarvi. a station in the northern hemisphere geomagnetically conjugate to Kerguelen.

other periodicities and for other island stations. Such work is in progress and will be reported later.

\subsection{7-day oscillation in mean dailv $H$ field}

Mean daily field of $H$ at low latitudes, to a considerable extent, represents the intensity of the ring current (Bhargava and Rao 1970). Spectra derived from the mean daily field once again indicate a dominant 27 -day oscillation. Power density variation as a function of geographic as well as dipole latitude is shown in figure 7 . Since the ring current field will be symmetric with respect to the equator, moduli of latitudes (positive values) only are considered. It is evident that there is a systematic decrease of the strength of the solar rotation signal with latitude. Kerguelen which indicated anomalous local time dependance again deviates from the linear trend. Correlation of the strength of the signal appears slightly better with geographic as compared to dipole latitude.

If the 27-day oscillation of mean daily field arose on account of an equatorial ring current alone, one would expect the power density for the 27-day oscillation to show an approximately $\cos ^{2} \theta$ dependance on the dipole latitude in the low- and midlatitudes. However, we find that the calculated power densities show an almost linear dependance on the dipole latitude and the geographic latitude. The slightly better correlation of the signal strength with geographic latitude than with dipole latitude once again cannot be explained on the basis of ring current modulation. Bhargava and Rao (1970) have pointed out that during the minimum activity phase of a solar cycle, the solar daily variation appears to dominate over the ring current effects even in the mean daily field and as we have observed earlier for the Indian zone, during this phase 


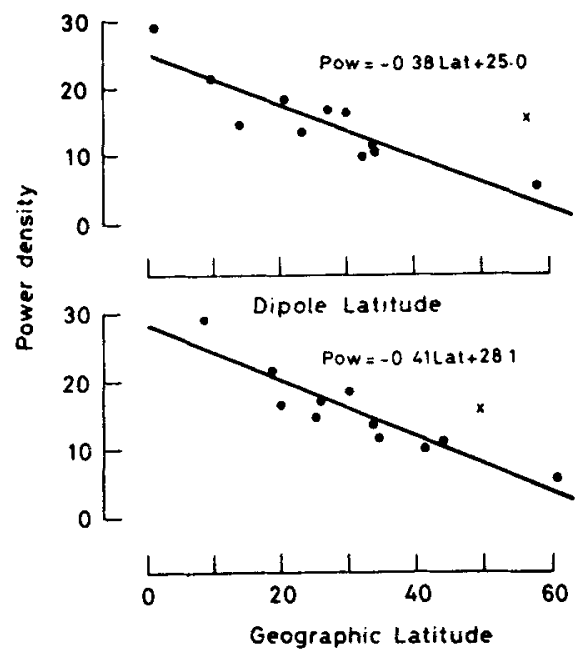

Figure 7. Dependance of power density for the 28-day signal in mean daily values of $H$ on dipole latitude (top) and on geographic latitude (bottom). Straight lines are least squares fits with adjustment made for the anomalous behaviour at Kerguelen (marked by $\mathrm{X}$ ).

of a solar cycle, the solar daily variation undergoes 27-day oscillations possibly through the ionospheric wind system. This wind system is controlled by the geographic equator and this calls for a more organised dependance of the 27-day power density of the mean daily field on the geographic latitude. In the presence of transient causes such as solar flares it would be difficult to detect this 27-day oscillation of the ionospheric wind system. Hence the period that we have chosen for our analysis as being totally free of such transient solar activity, enabled us to pick up this signal.

\section{References}

Bhargava B N $1973 J$. Atmos. Terr. Phys. 35567

Bhargava B N and Rangarajan G K 1975 J. Geomag. Geoelectr. 27257

Bhargava B N and Rao D R K 1970 Planet. Space Sci. 18287

Briggs B H 1979 XVII IUGG Gen. Assembly Abstract E 2.09 p. 375

Crooker N U and Siscoe G L. 1981 J. Geophys. Res. 8611201

Fukushima N and Kamide Y 1973 Radio Sci. 81013

Hansen R T, Hansen S F and Sawyer C 1976 Planet. Space Sci. 24381

Kane R P 1978 J. Geophys. Res. 835312

Legrand J P and Simon P A 1981 Solar Phys. 70173

Mayaud P N 1970 Ann. Geophys. 26109

Onwumechilli A 1967 in Physics of geomagnetic phenomena (eds) S Matsushita and W H Campbell (New York: Academic Press) p. 436

Price A T 1969 Space Sci. Rev. 9151

Rangarajan G K and Bhargava B N 1974 Proc. Indian Acad. Sci. (Earth Planet. Sci.), A80 249

Rangarajan G K 1979 Proc. Int. Workshop on selected topics of magnetospheric physics, Japanese IMS Committee, Japan p. 316

Rangarajan G K and Ahmed K 1981 Indian J. Radio Space Phys. 1020

Rush C M and Richmond A D 1973 J. Atmos. Terr. Phys. 351171

Srivastava B J and Prasad S N 1979 Geophys. J. R. Astr. Soc. 57159

van Hollebeke M A I, McDonald F B, Trainor J H and von Rosenvinge T T 1981 Solar wind four Report No. MPAE-W-I00-81-31, Proc. of Burghausen conference, p. 497 